\title{
ARTICLE OPEN \\ One-step synthesis of a steel-polymer wool for oil-water separation and absorption
}

\author{
Ali T. Abdulhussein ${ }^{1}$, Ganesh K. Kannarpady ${ }^{1}$ and Alexandru S. Biris ${ }^{1}$
}

Methods for the efficient and affordable remediation of oil spills and chemical leaks are crucially needed in today's environment. In this study, we have developed a simple, magnetic, porous material based on polydimethylsiloxane (PDMS) and steel wool (SW) that can fulfill these needs. The PDMS-SW presented here is superhydrophobic, superoleophilic, and capable of absorbing and separating oils and organic solvents from water. The material is mechanically and chemically stable, even in salty environments, and can be magnetically guided. It exhibits good selectivity, recyclability, and sorption capacity, and can quickly and continuously absorb and remove large amounts of oils and organic solutions from stationary and turbulent water. In addition, PDMS-SW's inherently high porosity enables direct, gravity-driven oil-water separation with permeate flux as high as $\sim 32,000 \mathrm{~L} / \mathrm{m}^{2} \cdot \mathrm{h}$ and separation efficiency over $99 \%$. The solution immersion process used to prepare the material is easily scalable and requires only a single step. Thus, with its demonstrated combination of affordability, efficiency, and ease of use, PDMS-SW has the potential to meet the demands of large-area oil and chemical clean-ups.

npj Clean Water (2019)2:10; https://doi.org/10.1038/s41545-019-0034-1

\section{INTRODUCTION}

The global, rapidly increasing use of oil as a main source of energy has led to frequent marine oil exploitation and transportation. Unfortunately, this increased marine-oil interaction has resulted in catastrophes such as oil spills and chemical leaks. ${ }^{1}$ Spilled oils and organic solvents harm both the environment and the economy. ${ }^{2-4}$ For example, in 2010, around 5 million barrels of crude oil spilled into the Gulf of Mexico, killing many marine animals and organisms and costing $\$ 600$ million.,6 Therefore, efficient, effective methods for cleaning up oil and chemical spills in salt and fresh water are desperately needed.

Methods such as in situ burning, dispersing factors, solidifiers, enhanced bioremediation, skimmers, and booms have been utilized to clean up oil spills, but they generally have low separation efficiency, limited sorption capacity and recyclability, and high operation costs, and they can even introduce secondary pollution during the clean-up process. ${ }^{7-10}$ Solutions that use superwetting materials have also been explored, mainly based on absorbency treatment and direct oil-water separation (filtration treatment), and encouraging outcomes have been achieved. ${ }^{11,12} \mathrm{~A}$ wide range of superwetting materials that are superhydrophobic, superoleophilic, and superoleophobic under water have shown significant promise for oil-water separation, ${ }^{13,14}$ including carbonaceous hydrogels/aerogels, ${ }^{15}$ sponges, ${ }^{16}$ and films ${ }^{17}$ and manganese nanowires. ${ }^{18}$ However, the costly, toxic reagents/ equipment and complex, lengthy fabrication methods and technologies required to create these materials limit their practical use.

Inorganic mineral products, $^{19}$ natural sorbent materials, ${ }^{20}$ artificial organic polymer absorbents, ${ }^{21}$ surface-treated polyurethane, ${ }^{22}$ inorganic or metallic-based meshes, ${ }^{23}$ and membranes $^{24,25}$ have also been developed to separate oil and water. Unfortunately, most of these materials suffer from poor separation efficiency, lack of selectivity, low absorption capacity, inconvenient recycling, low stability, low flux, or degradation and polymer swelling, severely hampering their practicality. ${ }^{9,26}$ Thus, a solution for oil spills and chemical leaks is still needed. Ideally, this solution would be a versatile material with low fabrication costs and stable performance in both fresh and salt water environments, able to be used as both a highly efficient absorbent (high capacity, selectivity, recyclability, and reusability) and a separator with high separation efficiency, high permeate flux, and low power.

In the oil-water separation field, "smart sorbents" are gaining popularity; these materials' absorption properties can be controlled by electrical, phonetic, thermal, or magnetic input. ${ }^{27}$ of these inputs, magnetically controllable absorbents have recently received great interest, as they can be easily driven to the contaminated area simply by exploiting the magnetic field. Researchers have integrated and tested various water-repellent tools with magnetic materials. ${ }^{5,14,28-32}$ To date, three main strategies have been used to synthesize magnetic absorbents. ${ }^{27}$ The first method involves depositing a magnetic layer on the porous absorbent's surface. This method has two major potential disadvantages: (1) it can decrease the pore volume, which impacts absorption capacity, particularly if the magnetic particles are larger than microns, ${ }^{33}$ and (2) the magnetic coatings might not be stable, meaning that, in order to recycle the absorbent, repeating the deposition and synthesis procedures will generally be necessary. ${ }^{28}$ The second strategy involves polymerizing superhydrophobic absorbents with magnetic nanoparticles, but production costs are high, and most of the products collapse or fracture under compression or stretching. The final method entails integrating polymeric materials with magnetic nanotubes, ${ }^{27}$ but it requires expensive nanomaterials and multiple, lengthy preparation steps, prohibiting large-scale fabrication.

${ }^{1}$ Center for Integrative Nanotechnology Sciences, University of Arkansas Little Rock, 2801 South University Avenue, Little Rock, AR 72204, USA

Correspondence: Ganesh K. Kannarpady (gkkannarpady@ualr.edu) or Alexandru S. Biris (asbiris@ualr.edu)

Received: 9 July 2018 Accepted: 22 February 2019

Published online: 16 April 2019 
In summary, creating magnetic separators tends to be costly and complex, requiring magnetic nanoparticles/materials, and most have exhibited poor oil-water separation properties, such as low selectivity, poor recyclability/reusability, and low absorption capacity and stability. Ideal magnetic absorbent materials would be produced in one step without the need for magnetic nanomaterials. In this study, we report for the first time a onestep, simple, and affordable solution immersion method to fabricate superhydrophobic, superoleophilic, and magnetic polydimethylsiloxane (PDMS)-modified steel wool (SW) for oil-water separation and absorption. This novel product does not require extra nanomaterials or complicated techniques. The PDMS-coated SW (PDMS-SW) absorbs various oils and organic solvents with high selectivity and sorption/separation capacities, outstanding recyclability, and excellent chemical, mechanical, and environmental stability. Because of its inherent magnetization, the modified SW can be guided by a magnet to selectively absorb oils floating on the water's surface. In addition, the PDMS-SW can be utilized in conjunction with a vacuum apparatus to continuously absorb and remove oil pollutants from water in both calm and turbulent conditions, suggesting its usability for large-scale removal of oil pollutants in both pure and salty environments. In gravity-driven oil-water separation experiments, the material exhibited high separation efficiency and high flux, as well as effective oil separation in salty water.

\section{RESULTS AND DISCUSSION}

Fabrication and characterization of the PDMS-modified SW material

Steel wool was chosen as the base material because it is porous, affordable, inherently magnetic, and commercially available; it also features high flexibility and mechanical stability that can be mass produced. PDMS was chosen as the coating because it is a commercially available silicone rubber that has high flexibility and mechanical stability. ${ }^{34}$ PDMS can be irreversibly bound to many materials and itself without adhesives. ${ }^{34}$ In addition, it can be used with SW without altering the wool's inherent magnetization.

To create the oil-absorbent material, we dipped commercially available SW samples in a toluene solution containing PDMS, then followed this with a heat treatment. A schematic of this simple, fast preparation process is shown in Fig. 1; to the best of our knowledge, no one else has reported modifying commercial SW to enable its use for oil/water separation. The overarching rationale

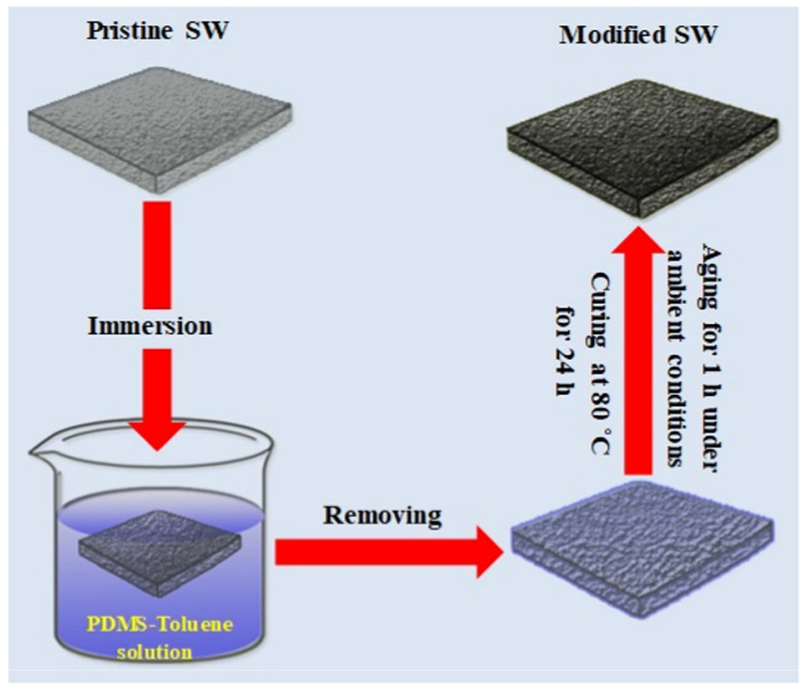

Fig. 1 Schematic diagram of the fabrication process used to create the polydimethylsiloxane-modified steel wool behind this preparation method and materials is as follows. First, it is easier and more practical to use a material that is commercially available than to find or create new materials. Second, the process is one step, simple, and cost effective and does not require extra (costly) nanoparticles, special chemicals, or complex treatments.

We utilized scanning electron microscopy (SEM) to study the microstructural morphology of the SW before and after PDMS modification. Figure $2 \mathrm{a}$, $\mathrm{d}$ shows that the SW has an open porous network with uniform steel microfibers that are $25 \mu \mathrm{m}$ in diameter, and the pores are different sizes, approximately $70 \pm 20 \mu \mathrm{m}$ on average. The wool's open porous network helps it to rapidly uptake and transport oils, chemical solvents, outer gases, and other liquids. Importantly, SEM analysis indicated that this porous structure is nearly the same before and after PDMS coating, demonstrating that the modification did not damage the pristine structure of SW or block its pores. SEM micrographs at higher magnifications revealed that a pristine single SW fiber has a rough surface consisting of hierarchical structures (Fig. 2b, c). SEM images also showed that, while the dip-coating process covered the fiber's rough surface with a thin waxy PDMS film (Fig. 2e, f), the modified SW had retained most of its original roughness. From these results, we can conclude that the wool's hierarchical structures, together with its micro-porous architecture, formed a composite interface in which air can be trapped beneath water within the surface's asperities, leading to superhydrophobicity (the Cassie-Baxter model). ${ }^{35}$

To further confirm that the SW was successfully modified by PDMS, we analyzed the surface chemistry of both the pristine and modified SW with X-ray photoelectron spectroscopy (XPS) (Fig. 3). XPS identified the SW's main elemental peaks to be $\mathrm{C} 1 \mathrm{~s}, \mathrm{O} 1 \mathrm{~s}, \mathrm{Si}$ $2 \mathrm{p}$, and $\mathrm{Si} 2 \mathrm{~s}$, with binding energies around 285, 532, 102, and $154 \mathrm{eV}$, respectively. New silicon peaks (Si $2 \mathrm{p}$ and Si $2 \mathrm{~s}$ ) appeared in the wide-scan spectrum for the modified SW, demonstrating that the Si-containing PDMS layer was incorporated successfully onto the SW's fibers. In comparison with the pristine SW's widescan spectrum, the modified SW did not have an N 1s or Fe 1s peak, indicating that the SW was well coated with PDMS. Furthermore, elemental mapping analysis on the surface of a PDMS-coated single fiber demonstrated clearly that $\mathrm{Si}$ was uniformly distributed throughout the whole fiber (Fig. 4), confirming successful coating by PDMS.

The pristine SW displayed superhydrophilic and superoleophilic properties (see Supplementary Fig. S1). However, after being coated with PDMS, the SW floated on the water's surface without taking in water (Fig. 5a); in contrast, the unmodified SW dropped to the bottom of the beaker. Figure $5 a$ inset shows that the surface of the PDMS-SW looked like a silver mirror when held underwater by external pressure, a phenomenon that indicates that air was trapped between the solid interface and the water, thus confirming that the PDMS-SW aligned with the non-wetting Cassie-Baxter model. The superhydrophobicity of the modified wool also caused deposited water droplets to form a nearly spherical shape (Fig. 5b). In addition to its superhydrophobicity, the modified SW showed excellent superoleophilicity-when motor oil was dropped onto its surface, the oil was absorbed immediately (Fig. 5b).

Clearly, the hierarchical structures and PDMS coating on the SW, combined with the wool's micro-porosity, made it superhydrophobic and superoleophilic. However, as is the case for a number of porous materials, it was difficult to precisely measure the superhydrophobicity of the modified SW using the water contact angle method. ${ }^{36}$ This is because the water droplets were supported by the fibers of the SW, making the contact line between surface and droplet unobtainable, which is necessary for defining the contact angle (see Supplementary Fig. S2). Thus water droplet bouncing was used instead. ${ }^{37}$ An $8-\mu$ l water droplet was dropped onto the PDMS-SW surface from a height of $20 \mathrm{~mm}$, with a high-speed camera recording the bouncing process. The 

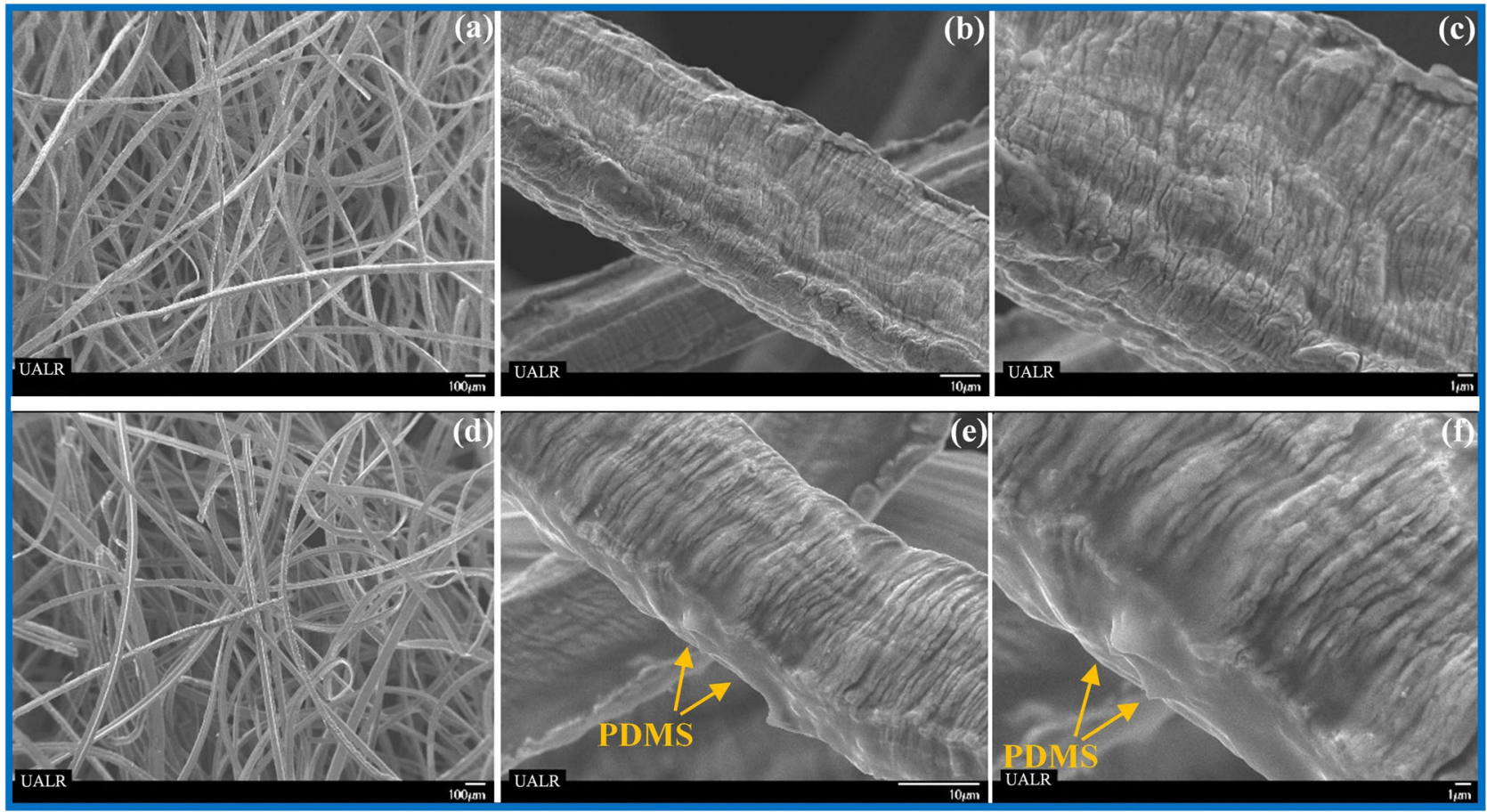

Fig. 2 Scanning electron microscopic images of a the original steel wool (SW), b a single SW fiber, $\mathbf{c}$ the single fiber at high magnification, d the modified SW, e polydimethylsiloxane (PDMS)-coated single fiber, and $f$ PDMS-coated single fiber at high magnification
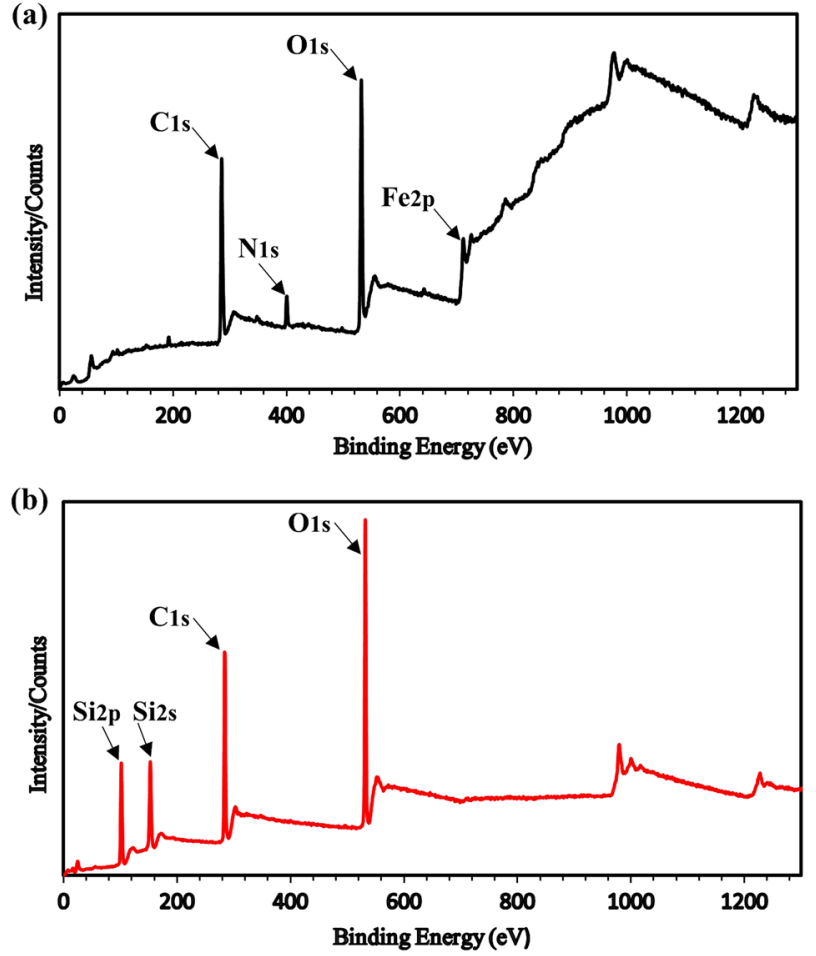

Fig. 3 The X-ray photoelectron spectroscopic spectra of a the original and $\mathbf{b}$ the modified steel wool

water droplet bounced off the modified SW easily, impinging the surface then bouncing off instantly, thus indicating high superhydrophobicity and low adhesion (see Supplementary Video S1). The potential energy of the droplet was converted to vibrational energy, causing it to rebound before undergoing damp oscillations and ultimately resting on the modified wool surface in a near-spherical shape. ${ }^{38,39}$ In contrast, the oil droplet was absorbed by the modified SW instantly (see Supplementary Video S2). These results confirmed the simultaneous superhydrophobicity and superoleophilicity of the modified SW, suggesting its potential for real-world, selective oil separation and absorption from water.

Selective absorption by the modified SW

We performed two types of tests to evaluate the modified SW's ability to selectively absorb oils/organic solvents in water. The first test was performed on floating oil (see Supplementary Fig. S3, Fig. $6 a$, and Supplementary Video S3). An external magnet was used to control the PDMS-SW's direction on the surface of the oil-water mixture, guiding it to the contaminated area. The magnetically guided material quickly absorbed the floating oil (colored with Sudan red) in the contaminated area, leaving only water underneath. The wool was then taken out of the solution. From start to finish, the procedure took only a few seconds. In the second test, we investigated the wool's ability to selectively absorb oil under water, using dichloromethane (colored by Sudan red) as the oil because it sinks in water due to its high density. When we immersed the modified wool in the dichloromethanecontaminated water by an external force, all the oil was rapidly - within a few seconds-sucked up into the wool upon contact, leaving clean, clear water with no sign of colored oil when the wool was taken out (Fig. 6b and Supplementary Video S4). These rapid absorption kinetics result from the modified wool's oleophilicity, capillaries, and high porosity.

The PDMS-SW showed high absorption capacities - up to 12-27 times its own weight-for common oils and organic solvents, depending on the organic liquid's density, viscosity, and surface tension (Fig. 7a). This absorption capacity is higher than that of several absorbents reported recently for similar organic liquids, including a PDMS sponge $(5-11 \mathrm{~g} / \mathrm{g}),{ }^{40}$ aerogel composite $(2-16 \mathrm{~g} / \mathrm{g}){ }^{41}$ nitrogen-rich carbon aerogel $(5-16 \mathrm{~g} / \mathrm{g}){ }^{42}$ magnetic composite foam $(13 \mathrm{~g} / \mathrm{g}){ }^{28}$ magnetic silicone sponge $(7-17 \mathrm{~g} / \mathrm{g}){ }^{30}$ nanowire membrane $(<20 \mathrm{~g} / \mathrm{g}){ }^{18}$ and polypropylene sponges $(5-20 \mathrm{~g} / \mathrm{g}) .{ }^{43}$ In addition, although the capacity of the modified SW 

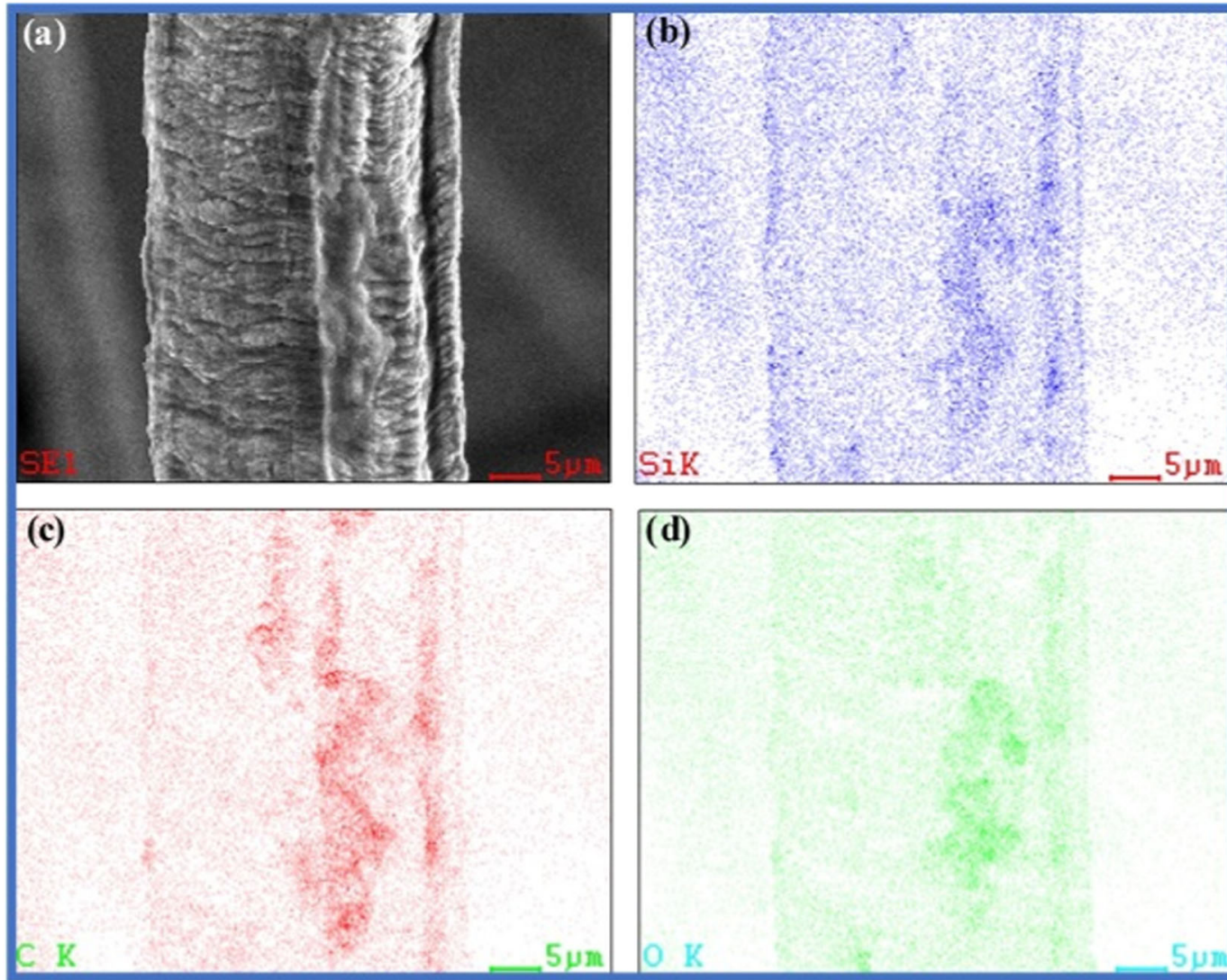

(d)

Fig. 4 a Scanning electron microscopic image of polydimethylsiloxane-coated single fiber; $\mathbf{b}$-d energy-dispersive X-ray spectroscopic element mapping of $\mathrm{Si}, \mathrm{C}$, and $\mathrm{O}$, respectively
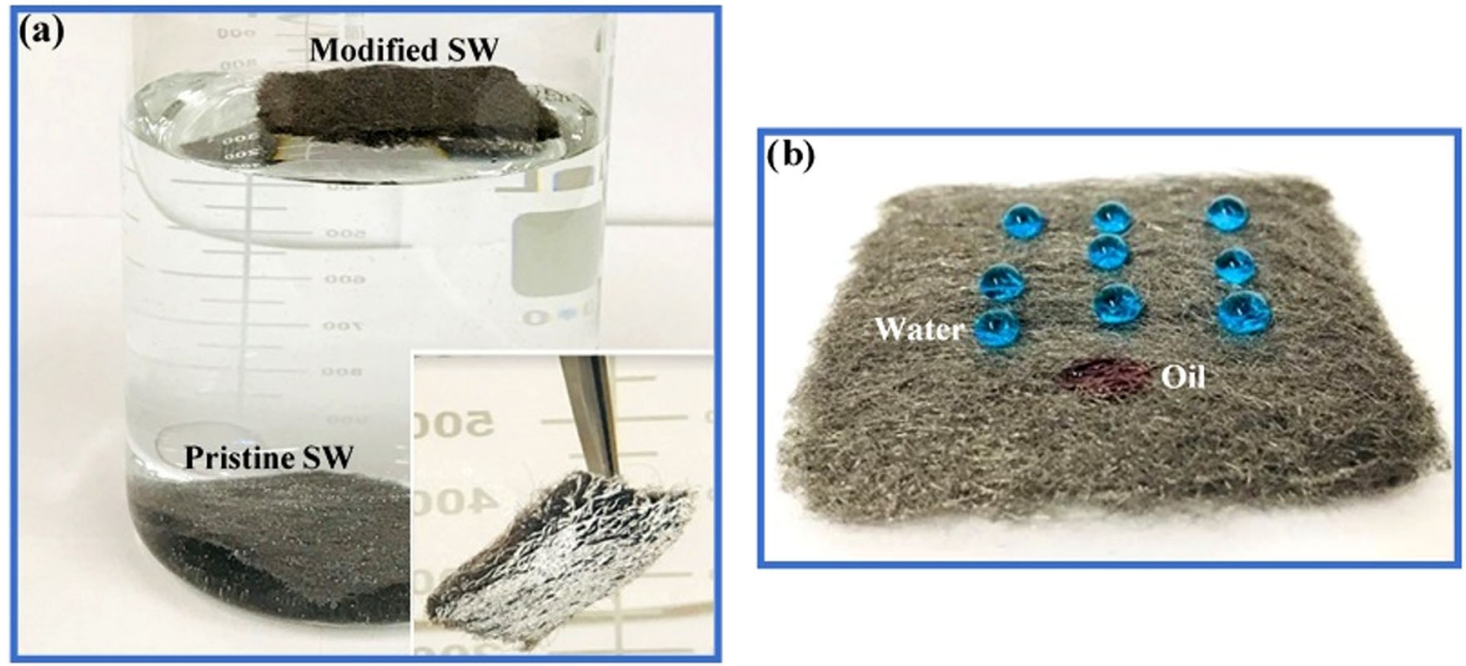

Fig. 5 a Photograph of the original and modified steel wools (SWs) after being placed in water. Inset: photograph of the modified SW after immersion in water by force; b photograph of water droplets (blue) as semi-spheres and motor oil (red) on the surface of the modified SW

is lower than that of other absorbents, such as new carbon sponges, ${ }^{29,44,45}$ films, $^{26}$ and aerogels, ${ }^{4}$ these sorbents require costly fabrication materials, special chemicals, and complicated, lengthy processes, limiting their mass production. In contrast, the preparation method for the PDMS-SW is one step, simple, easily scaled up, and cost effective, and no expensive raw materials, special chemicals or nanoparticles, or complex equipment are required. Therefore, from methodology to cost to versatility, our modified SW offers major advantages over current options for cleaning organic leaks and oil spills.

\section{Recyclability of the modified SW}

Recyclability and absorbate retrievability are key considerations when designing materials to remove oils and organic solvents, due to the need for environmental and economic sustainability. Our modified SW satisfies both considerations, as demonstrated by mechanical squeezing tests (Fig. 7b). Hexane and motor oil were selected as the model absorbates for investigating the PDMS-SW's cyclic absorption/squeezing behavior. Figure 7c, d shows the recyclability of the modified SW for hexane and motor 

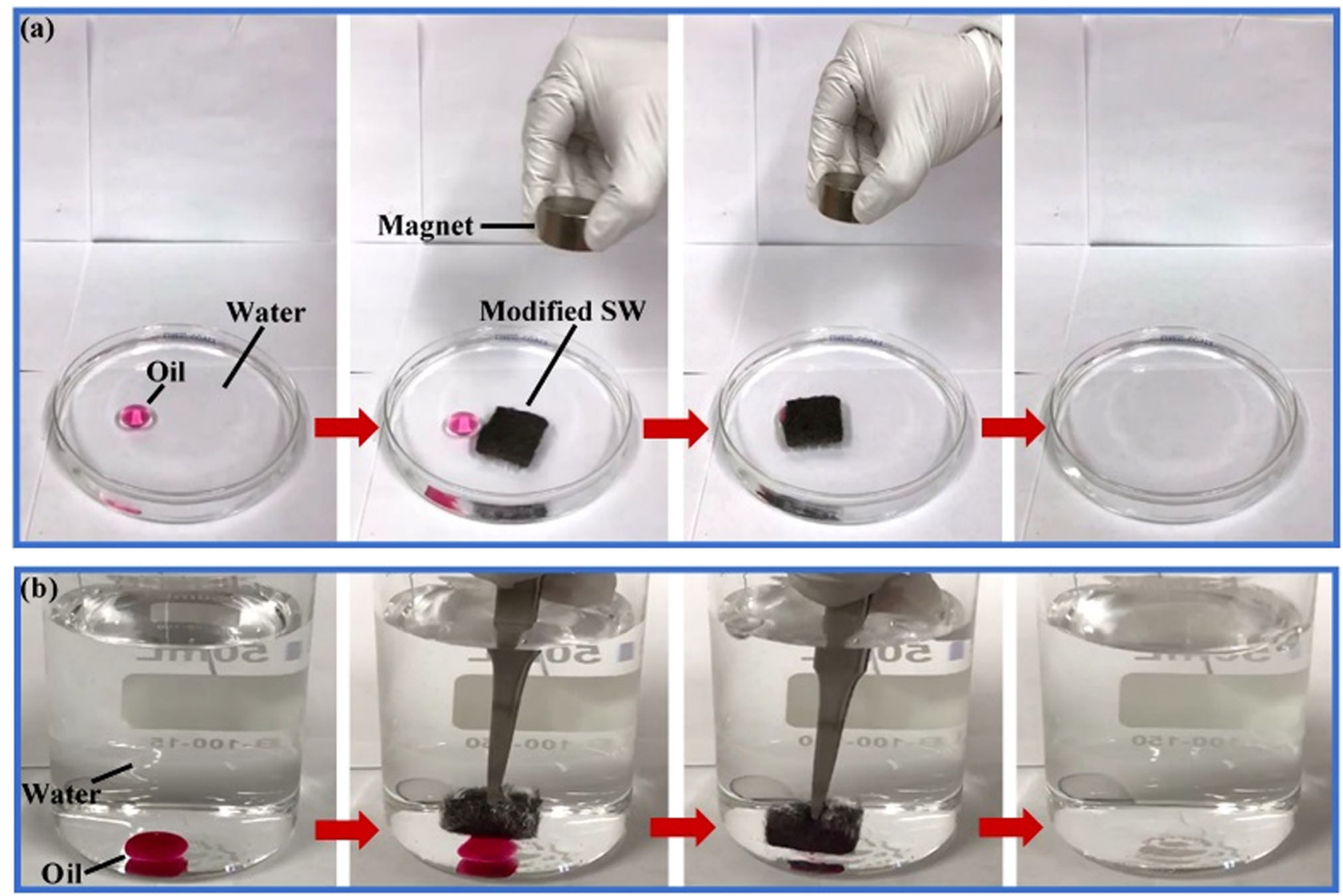

Fig. 6 Photographs of the modified steel wool a being guided by a magnet to remove floating oil and $\mathbf{b}$ absorbing dichloromethane at the bottom of a beaker

oil, respectively, through 100 cycles. The results demonstrate that, because of the PDMS-SW's elasticity, absorbates stored in its macrospores were able to be retrieved by mechanical squeezing. In addition, the porous structure of the modified SW stayed the same after multiple cycles of absorption/squeezing. The simplest process for releasing an organic liquid, mechanical squeezing is faster and more eco-safe and cost-effective than other reported recycling processes, such as heat treatment ${ }^{4}$ and burning. ${ }^{7}$ For hexane, the modified SW showed high recyclability, even after 100 absorption/retrieval cycles, with the absorbance capacity largely remaining the same. However, for the viscous oil (motor oil), a slight reduction in oil absorbance capacity was observed over the 100 cycles. This deterioration is due to residual oil remaining inside the pores of the modified SW because it could not be totally removed after squeezing the wool through that many cycles.

Rinsing with strong organic solvents such as dichloromethane, trichloroethane, or dimethylformamide could be a good option for removing residual oil that cannot be recovered sufficiently by ethanol or acetone. For example, many materials, such as surfacetreated polyurethane, ${ }^{46}$ organic fibrous sorbents, ${ }^{47}$ and siliconetreated textiles, ${ }^{48}$ have shown high absorption capacity, but their recyclability was not satisfactory because certain oils stayed in their pores and could not be adequately retrieved by alcohol or acetone due to low solubility in these solvents. However, rinsing with the powerful organic liquids listed above would dissolve these absorbents easily, rendering them useless. ${ }^{26}$ In contrast, the modified SW had high stability with these organic solvents (see Supplementary Fig. S4); after rinsing with dichloromethane and drying at $80^{\circ} \mathrm{C}$ for several hours, the PDMS-SW showed roughly the same absorption capacity as it did when fresh. Together, these results affirm the high recyclability and reusability of the PDMSSW.
Continuous absorption of various contaminants in multiple conditions

In addition to being highly absorbent and recyclable, the ideal clean-up material would be able to continuously absorb and remove large amounts of oil and organic solvents from water. As illustrated in Fig. 8a, we investigated our modified wool's ability to perform such continuous absorption. A small piece of the modified wool was folded and crammed into the end of a narrow tube, then that end was fixed in a beaker containing oil (toluene) and water; the water was colored blue to distinguish it from the clear toluene. The tube's other end was connected to a vacuum pump by the filter flask. The modified wool absorbed the toluene quickly and repelled water completely. In addition, the toluene was absorbed and removed simultaneously by the wool piece when the vacuum system was turned on. A toluene stream formed in the tube, and the oil was gradually sucked out of the water. Eventually, all the toluene was completely removed from the water's surface, leaving only blue water in the beaker. The retrieved toluene was collected into the filter flask, and no water droplets were seen in it.

This experiment was also carried out with other contaminants in water: sesame oil, mineral oil, gasoline, and n-hexadecane. The modified SW completely separated the oils/organic solvent pollutants from the water surface (see Supplementary Figs S5S8), without absorbing any water. The PDMS-SW's separation efficiency for sesame oil, mineral oil, gasoline, and $n$-hexadecane was 99.5, 99.3, 99.7, and 99.6, respectively. Furthermore, at least $25 \mathrm{~L}$ of gasoline were able to be continuously collected by the modified wool with a separation efficiency of $99.7 \%$, as well as high working stability. Therefore, the PDMS-SW has excellent selective oil-water separation efficiency. 

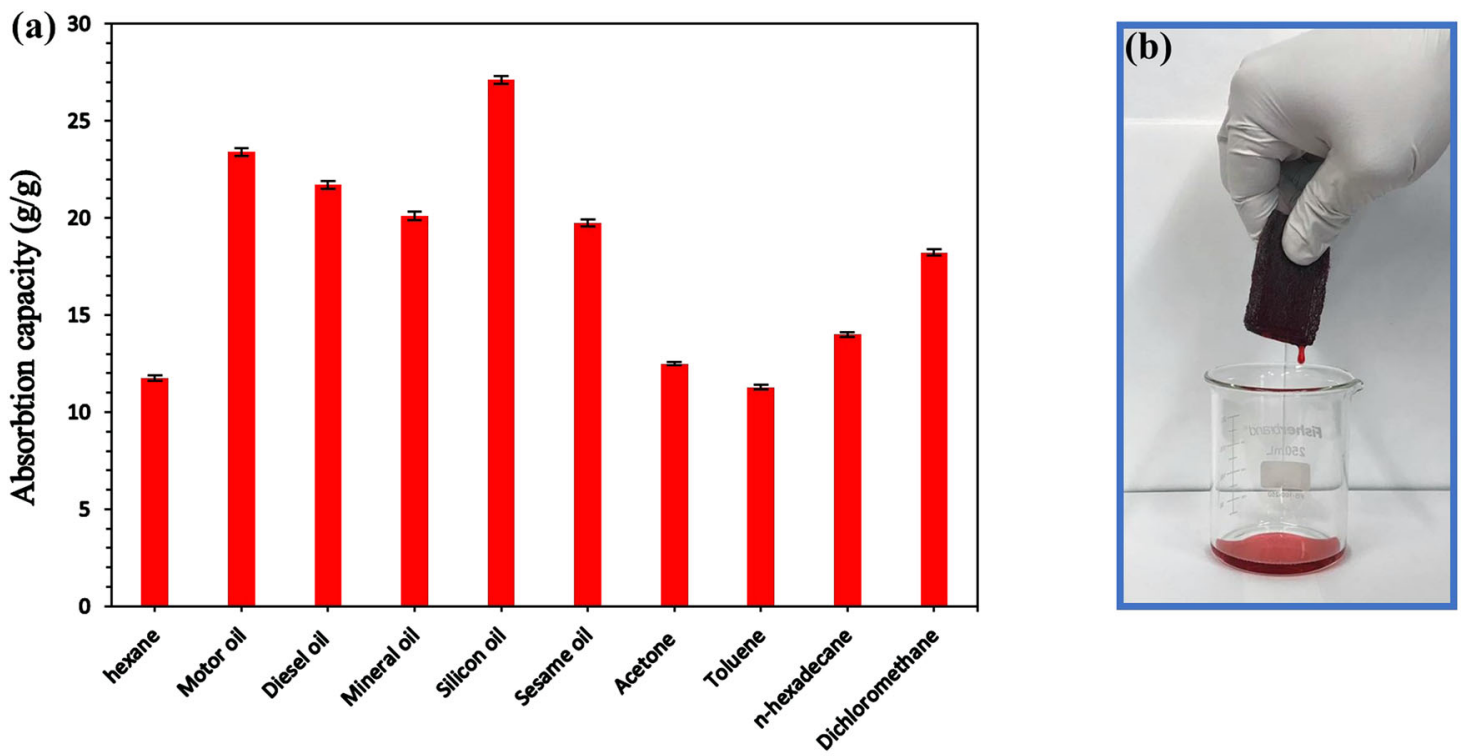

(c)

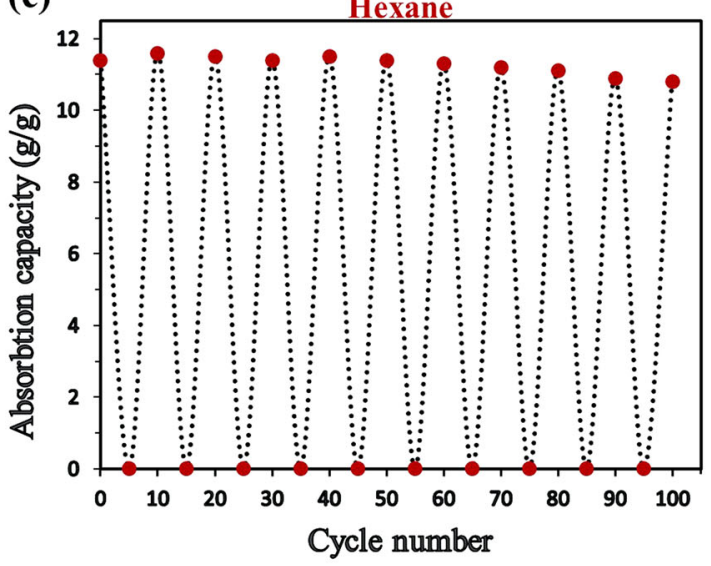

(d)

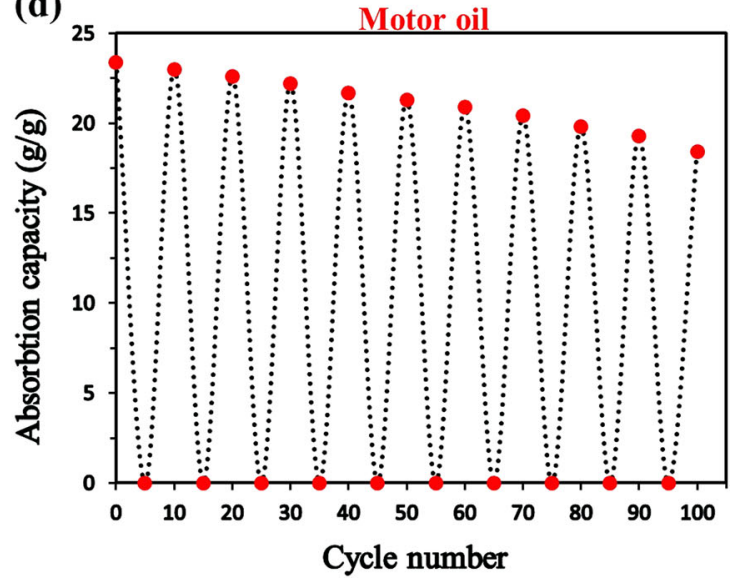

Fig. 7 a Absorption capacity of the modified steel wool (SW) for different oils and organic solvents; $\mathbf{b}$ collection of motor oil from the modified SW by simple mechanical squeezing; $\mathbf{c}$, d the absorption capacity of the modified SW for hexane and motor oil, respectively, over 100 cycles

In real environments, such as the sea or a river, water is usually in motion rather than stationary, as it generally is in laboratory testing. Therefore, to mimic actual oil-polluted water conditions, we repeated the previous experiments under highly turbulent conditions. To create a turbulent effect, about $400 \mathrm{~mL}$ of toluene were added to a similar amount of water, and the mixture was strongly stirred via a magnetic bar at $\sim 1080 \mathrm{rpm}$ to cause oil droplets to form in the water. We then began the vacuum-aided process with an applied vacuum pressure of $5 \mathrm{kPa}$, as described above. The oil droplets were continuously separated from water once the vacuum was turned on, while the water was not impacted at all (Fig. 8b).

While some continuous absorbents have been developed, $, 6,7,49$ very few can continuously remove oil from seawater selectively and in both static and dynamic conditions, even though these are common environments for oil spills. Therefore, an inexpensive, salt-tolerant, superhydrophobic absorbent for efficient oil/seawater separation is urgently needed. To test our modified SW's potential to fill this need, we repeated the previous experiment but with a complex oil (toluene)/saltwater mixture. To mimic seawater, we added $3.5 \mathrm{wt} \% \mathrm{NaCl}$ to the water and mixed it well ${ }^{50}$ before turning on the vacuum. The PDMS-SW removed all the transparent oil from the surface while leaving all the colored water in the beaker (see Supplementary Video S5) - no water was visible with the naked eye in the retrieved oil. Furthermore, in around $7.25 \mathrm{~s}$, the PDMS-SW removed the same amount of oil as a PDMS-graphene sponge did in $30 \mathrm{~s}^{6}$

We also tested the modified wool's performance with the oil-saltwater mixture under highly turbulent conditions. The PDMS-SW continuously removed around $400 \mathrm{~mL}$ of toluene from the water, and no blue water was visible in the collected oil in the filtrate flask. The water level in the beaker was stable despite the lengthy continuous pumping, indicating that the water was unaffected by the modified SW. In addition, the separation efficiency was maintained at $99.9 \%$ (detailed procedure given in Supplementary Video S6).

The continuous, quick absorption performed by our inexpensive, simply prepared modified SW in fresh and saltwater offers a major advantage over other current absorbents, which require expensive, complicated fabrication and can rarely perform in saltwater. The results of all our tests show that the novel PDMS-SW has strong practical potential for continuously absorbing and removing large amounts of oil and organic solutions from water in fresh and marine environments. 
(a)
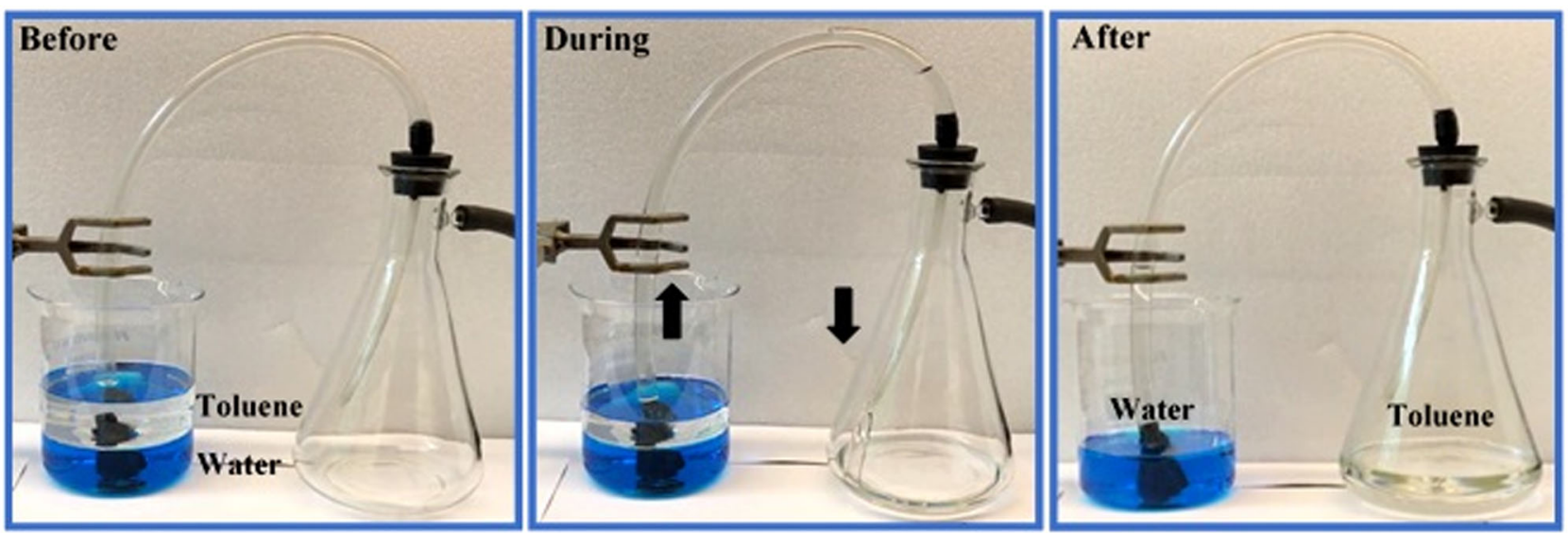

(b)
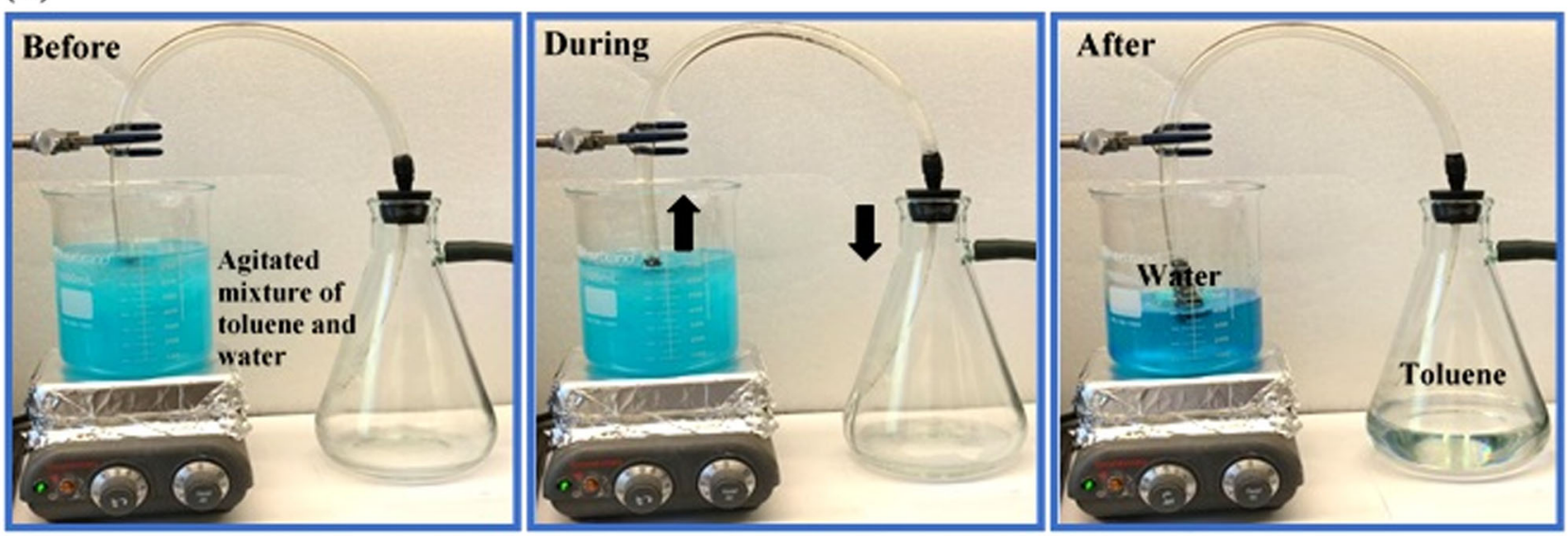

Fig. 8 Photographs show the continuous absorption and removal of toluene from $\mathbf{a}$ a nonturbulent oil-water mixture and $\mathbf{b}$ an oil-water mixture made turbulent by a magnetic stirring plate. The water was colored by methylene blue to enhance the visual impact

\section{Oil-water separation}

In addition to selective absorption, direct separation of oil from water is one of the main treatment techniques for addressing water pollution. Various materials have been used to fabricate superwetting surfaces, including metallic-based meshes, ${ }^{51-53}$ membranes, ${ }^{24,54}$ films, $^{55}$ and filter papers ${ }^{56}$. While these materials displayed high oil-water separation efficiency and selectivity, they also had a number of drawbacks, including complex fabrication, costly raw materials, and weak mechanical and chemical stability, limiting their large-scale production. Therefore, an efficient, scalable oil-water separator for oil spills that is cost effective and has low power consumption remains a serious need.

Given its superhydrophobic and superoleophilic nature and high flexibility, we believed our modified SW could fill this need. To test this potential, we conducted a practical oil/water separation experiment (Fig. 9a). First, a small piece of wool was cut $\left(60 \times 60 \times 7 \mathrm{~mm}^{3}\right)$, placed on stainless-steel mesh, and fixed between two glass beakers. A mixture of cyclohexane (colored with Sudan red) and water (colored with methylene blue) was prepared and poured onto the PDMS-SW. The cyclohexane was able to rapidly penetrate the separator and pass to the bottom of the beaker underneath it, driven solely by gravity (Fig. 9b). In contrast, the water was repelled by the modified SW and stayed in the upper beaker (Fig. 9c). The entire oil/water separation procedure was performed within a few seconds (see Supplementary Video S7) with no additional force, demonstrating the easiness and low energy consumption of the process. Therefore, the PDMS-SW clearly allowed oils to rapidly pass through it but prevented water from doing so, thus separating the two.

Furthermore, mixtures of toluene, gasoline, and sesame oil with water were effectively separated by the modified SW, with separation efficiency values reaching over 99\% (Fig. 9d). Owing to its robust coating adhesion, the modified SW retained its superhydrophobicity after 40 separations, as demonstrated by XPS analysis (see Supplementary Fig. S9) and a water droplet bouncing off the surface (see Supplementary Video S8). In addition, we repeated these oil/water separation experiments with saltwater (3.5\% salt). In a cyclohexane/saltwater mixture, the modified SW successfully separated the cyclohexane from the saltwater, with the separation efficiency staying $>99 \%$ (see Supplementary Fig. S10).

Permeate flux is an important factor for evaluating oil-water separation, as higher permeate flux results in faster separation. ${ }^{57,58}$ The modified SW displayed ultrafast separation of oil from water via gravity alone. Different oil fluxes that permeated through the PDMS-SW were evaluated and averaged after repeating 3 times; a 7-mm-thick wool sample was used. The average permeate flux values for the oils-toluene, gasoline, and cyclohexane-were $32,026.4 \pm 141.2, \quad 30,793.6 \pm 432.7$, and $27,029.1 \pm 315.2 \mathrm{~L} / \mathrm{m}^{2} \cdot \mathrm{h}$, respectively (Fig. 9e). These flux values are much higher than those of many advanced separators reported in the literature, including PFOTS-modified $\mathrm{SiO}_{2} /$ carbon stainless-steel mesh $(<1000){ }^{59}$ a carbon-silica nanofibrous membrane (1500-3000 L/ $\left.\mathrm{m}^{2} \cdot \mathrm{h}\right){ }^{58}$ a superhydrophobic and superoleophilic polyvinylidene fluoride membrane $\left(700-3500 \mathrm{~L} / \mathrm{m}^{2} \cdot \mathrm{h}\right),{ }^{60}$ and a polyethylene mesh 

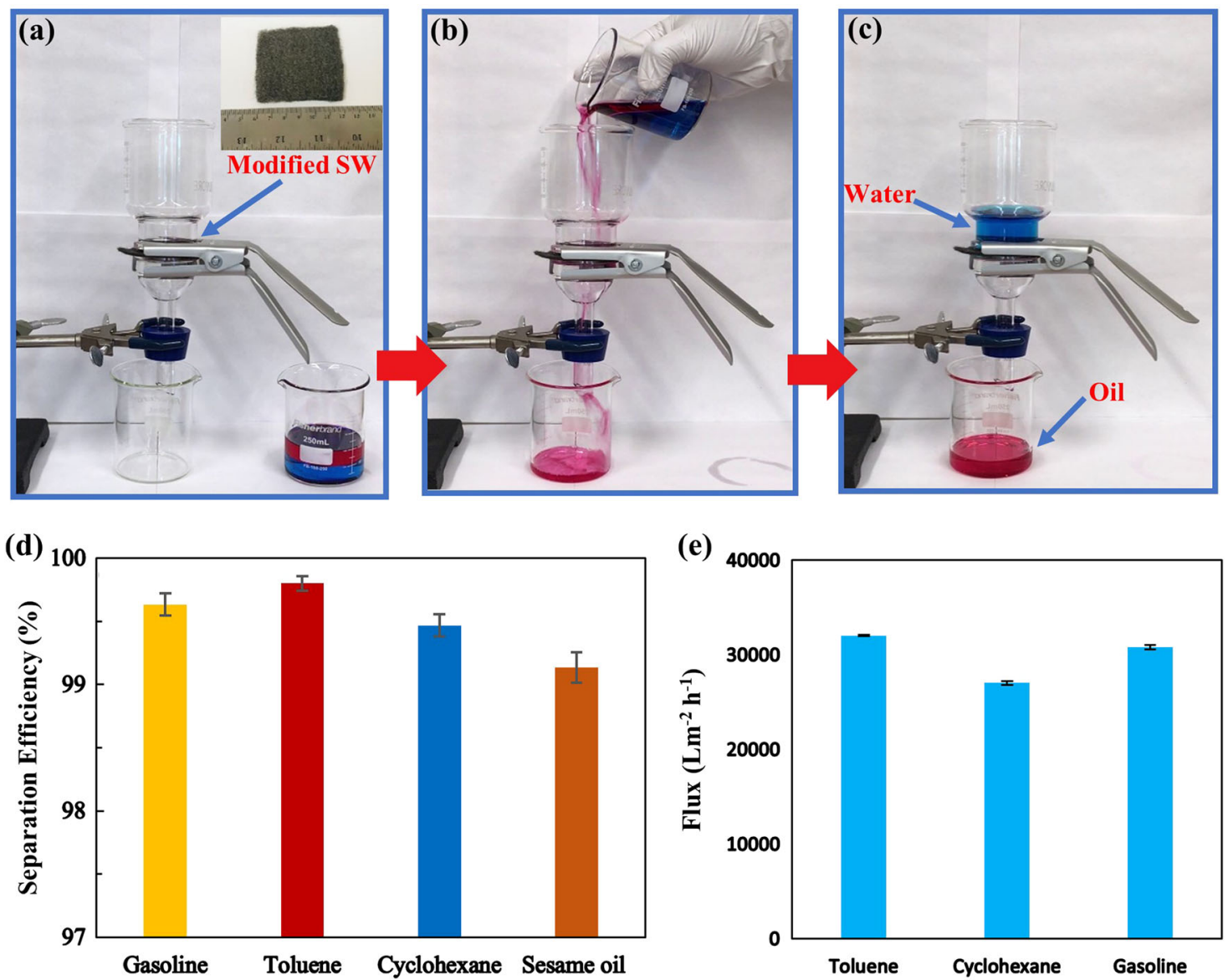

Fig. 9 Oil-water separation carried out by the modified steel wool (SW; oil dyed with Sudan red, water dyed with methylene blue): a before separation, $\mathbf{b}$ during separation, and $\mathbf{c}$ after separation (the separation process was driven by gravity). $\mathbf{d}$ Separation efficiency of the modified SW for various oil-water mixtures. e Flux for permeating different types of oils through the modified SW. The error bars indicate the standard deviations from triplicate measurements

$\left(<7500 \mathrm{~L} / \mathrm{m}^{2} \cdot \mathrm{h}\right) .^{57}$ The superoleophilic nature and open-pore network of the modified SW promoted this rapid mass transport. In summary, the PDMS-SW's high separation efficiency, ultrafast permeate flux $\left(25,000-33,000 \mathrm{~L} / \mathrm{m}^{2} \cdot \mathrm{h}\right)$, reusability, low-cost raw materials, simple preparation, scalability, and usability in salty environments make it a promising tool for real-world oil-water separation.

The PDMS-SW's water intrusion pressure $(P)$ was also investigated by determining the maximum water column height $\left(h_{\max }\right)$ that it could bear, via the following Eq. (1):

$$
P=\rho g h_{\max }
$$

where $\rho$ is the density of water, $g$ is the acceleration of gravity, and $h_{\max }$ represents the maximum height of water that the modified SW can support. The PDMS-SW was able to completely support a $\sim 14.6-\mathrm{cm}$-tall column of water (Fig. 10) without allowing any water to pass through it. Thus the water intrusion pressure for the modified SW is $1.43 \mathrm{kPa}$.

For the first time, to our knowledge, we have fabricated a superhydrophobic and superoleophilic PDMS-SW and demonstrated its efficient oil absorption and oil-water separation. The solution immersion method we used requires only a single, simple step, affordable materials, and no special chemicals or complicated equipment and, as a result, is easy to scale up. The highly porous PDMS-SW is also magnetic without the addition of expensive nanoparticles, which were previously considered required to make a material magnetic for this application. The modified SW's magnetic properties allow it to be guided without contact to oil-polluted areas. Moreover, after collecting contaminants and undergoing mechanical squeezing, the PDMS-SW can simply be driven back to the contaminated area to recover more spilled liquid. In addition, the PDMS-SW's raw materials can be commercially and affordably manufactured on a large scale. These factors make the PDMS-SW well suited for large-scale manufacturing and thus for large-scale removal of oil spills and clean-up of organic solvents from water. The modified SW not only shows high absorption performance, including high selectivity, high recyclability, and good capacity, but it can also continuously, quickly absorb and remove large amount of various oils/organic solvents from both calm and turbulent water. Furthermore, the PDMS-SW can separate oils from water with great efficiency. In addition, the oil-water separation process is ultrafast and solely gravity-driven. Finally, the modified SW performs highly stable absorption, even in salty environments. Based on the results of this study, we believe that the PDMS-modified SW is a promising material for water remediation, cleaning up large-scale oil spills, and oil recovery.

\section{METHODS}

\section{Materials}

SW (super fine with \#0000 grade code) was purchased from a local store in Arkansas, USA. PDMS (Sylgard 184) was purchased from Dow Corning, USA. Toluene, hexane, dichloromethane, cyclohexane, acetone, ethanol, nhexadecane, mineral oil, sesame oil, methylene blue, and Sudan red 7B were provided from Fisher Scientific Inc., USA. Motor oil, silicone oil, and diesel oil were obtained from a local store. Gasoline was purchased from a 


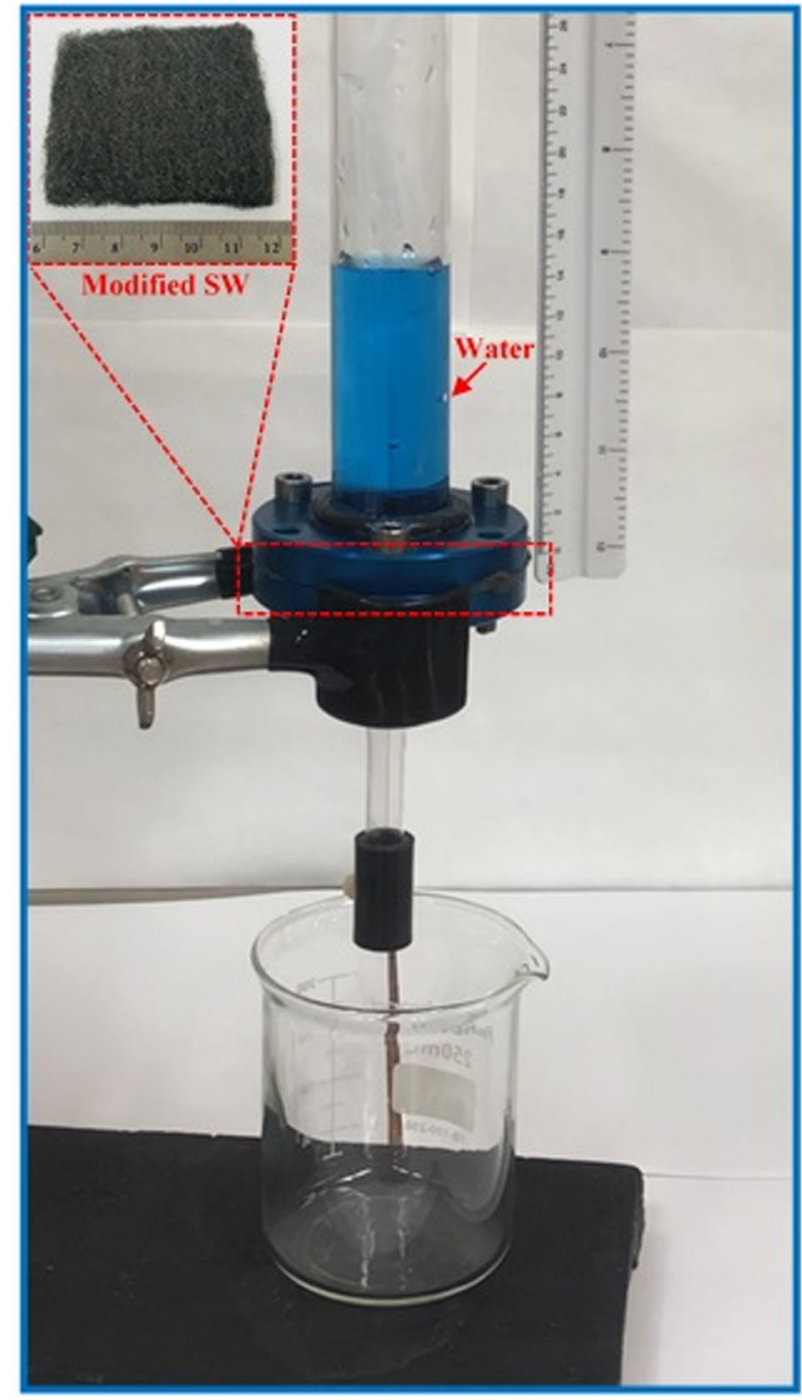

Fig. 10 Water intrusion pressure of the modified steel wool (water is dyed with methylene blue)

local Shell gas station. All chemicals were utilized as received without any purification.

\section{Fabrication}

PDMS (Sylgard 184) is a silicon elastomer that consists of two parts: an elastomer base and a curing agent to promote cross-linking and hardening in order to produce a heat-resistant polymer. Briefly, in this study, the polymer and cross-linking agent were added in a 10:1 weight ratio to $50 \mathrm{~mL}$ of toluene. The mixture underwent constant magnetic stirring for 30 min or until it was a clear solution. A piece of commercial SW was cut and cleaned ultrasonically in acetone for $15 \mathrm{~min}$. The $\mathrm{SW}$ piece was then put in the oven to dry at $80^{\circ} \mathrm{C}$ for several hours. After drying, the SW was immersed into the PDMS-toluene solution for $30 \mathrm{~s}$, removed and dried under atmospheric conditions for $1 \mathrm{~h}$, and then cured in the oven at $80^{\circ} \mathrm{C}$ for $24 \mathrm{~h}$ to obtain the final PDMS-modified SW.

\section{Characterization}

SEM was used to analyze the PDMS-modified SW's surface morphology (JEOL SEM7000FE). In addition, the modified SW's surface chemistry was analyzed using a Thermos Scientific K-Alpha X-ray photoelectron spectrometer. Elemental mapping was conducted using energy-dispersive $\mathrm{X}$-ray spectroscopy (Genesis spectrum). Water bouncing videos were taken by a high-speed digital camera (HiSpec 1) at a rate of 1000 frames per second. All measurements were performed at ambient temperature.

\section{Selective oil absorption and recyclability tests}

Various oils/organic solvents were used in the absorption experiments. For each type of oil/solvent, a piece of modified SW was immersed in the oil/ organic solvent until it was totally saturated, then removed and immediately weighed. The weight measurement should be carried out quickly to avoid any absorbate evaporation. The absorption capacity $(k)$ of the modified SW was determined in weight-gain ratio, as given in Eq. 2:

$k=\frac{W a-W b}{W b}(g / g)$

where $\mathrm{Wa}$ is the weight of the modified SW in the oil/organic solventsaturated state and $\mathrm{Wb}$ is the weight of the modified SW in the initial state. Each test was repeated three times.

The recyclability of the modified SW was evaluated by performing cyclic absorption-simple squeezing tests with two organic solutions, hexane and motor oil, separately. The absorption capacity was then calculated.

\section{Oil-water separation}

A piece of the PDMS-SW was placed on stainless-steel mesh and secured between two glass containers. Oil-water mixtures were then poured onto the modified SW, with gravity being the only driving separation force. Each separation experiment was performed three times, and the separation efficiency was determined by the following Eq. (3):

Separation efficiency $=\frac{\mathrm{Va}}{\mathrm{Vb}} \times 100 \%$

where $V a$ is the volume of water that remains on the surface of the modified SW after the oil-water mixture is poured and $\mathrm{Vb}$ is the volume of water in the oil-water mixture before pouring.

The flux $(F)$ of the modified SW was calculated by the following Eq. (4):

$F=\frac{V}{S t}$

where $V$ is the volume of the permeating liquid through the modified SW $S$ is the effective contact area of the modified SW, and $t$ is the permeating time.

\section{DATA AVAILABILITY}

All raw data used in this manuscript can be obtained for free by contacting the corresponding authors.

\section{ACKNOWLEDGEMENTS}

Funding for this research was provided by the Center for Advanced Surface Engineering, under the National Science Foundation Grant No. IIA-1457888 and the Arkansas EPSCoR Program, ASSET III. We thank Dr. Shawn Bourdo and Dr. Anindya Ghosh for their valuable feedback and discussion. We thank Bijay Chhetri for his help with preparing Fig. 1. The editorial assistance of Emily Davis is also acknowledged.

\section{AUTHOR CONTRIBUTIONS}

The authors originated the idea for the experiments collaboratively. A.T.A synthesized samples, carried out most of the characterization, and prepared the first draft of the manuscript. G.K.K. carried out XPS analysis and helped revise the manuscript. A.S.B. also helped revise the manuscript.

\section{ADDITIONAL INFORMATION}

Supplementary Information accompanies the paper on the npj Clean Water website (https://doi.org/10.1038/s41545-019-0034-1).

Competing interests: The authors declare no competing interests.

Publisher's note: Springer Nature remains neutral with regard to jurisdictional claims in published maps and institutional affiliations. 


\section{REFERENCES}

1. Hu, H., Zhao, Z., Gogotsi, Y. \& Qiu, J. Compressible carbon nanotube-graphene hybrid aerogels with superhydrophobicity and superoleophilicity for oil sorption. Environ. Sci. Technol. Lett. 1, 214-220 (2014).

2. Ge, J. et al. Joule-heated graphene-wrapped sponge enables fast clean-up of viscous crude-oil spill. Nat. Nanotechnol. 12, 434-440 (2017).

3. Wu, D., Yu, Z., Wu, W., Fang, L. \& Zhu, H. Continuous oil-water separation with surface modified sponge for cleanup of oil spills. RSC Adv. 4, 53514-53519 (2014).

4. Wu, Z.-Y. et al. Carbon nanofiber aerogels for emergent cleanup of oil spillage and chemical leakage under harsh conditions. Sci. Rep. 4, 4079 (2014).

5. Tran, V. H. T. \& Lee, B. K. Novel fabrication of a robust superhydrophobic $\mathrm{PU} @ Z n O @ \mathrm{Fe}_{3} \mathrm{O}_{4} @ S A$ sponge and its application in oil-water separations. Sci. Rep. 7, 1-12 (2017).

6. Tran, D. N. H., Kabiri, S., Sim, T. R. \& Losic, D. Selective adsorption of oil-water mixtures using polydimethylsiloxane (PDMS)-graphene sponges. Environ. Sci. Water Res. Technol. 1, 298-305 (2015).

7. Khosravi, M. \& Azizian, S. Synthesis of a novel highly oleophilic and highly hydrophobic sponge for rapid oil spill cleanup. ACS Appl. Mater. Interfaces 7, 25326-25333 (2015).

8. Abdulhussein, A. T. et al. Facile fabrication of a free-standing superhydrophobic and superoleophilic carbon nanofiber-polymer block that effectively absorbs oils and chemical pollutants from water. Vacuum 149, 39-47 (2018).

9. Shang, B., Wang, Y., Peng, B. \& Deng, Z. Bioinspired polydopamine particlesassisted construction of superhydrophobic surfaces for oil/water separation. $J$. Colloid Interface Sci. 482, 240-251 (2016).

10. Lin, J. et al. Facile control of intra-fiber porosity and inter-fiber voids in electrospun fibers for selective adsorption. Nanoscale 4, 5316 (2012).

11. Matin, A., Baig, U., Gondal, M. A., Akhtar, S. \& Zubair, S. M. Facile fabrication of superhydrophobic/superoleophilic microporous membranes by spray-coating ytterbium oxide particles for efficient oil-water separation. J. Memb. Sci. 548, 390-397 (2018).

12. Gondal, M. A. et al. Study of factors governing oil-water separation process using TiO2films prepared by spray deposition of nanoparticle dispersions. ACS Appl. Mater. Interfaces 6, 13422-13429 (2014).

13. Xue, Z. et al. A novel superhydrophilic and underwater superoleophobic hydrogel-coated mesh for oil/water separation. Adv. Mater. 23, 4270-4273 (2011).

14. Wu, L., Li, L., Li, B., Zhang, J. \& Wang, A. Magnetic, durable, and superhydrophobic polyurethane@ $\mathrm{Fe}_{3} \mathrm{O}_{4} @ \mathrm{SiO}_{2} @$ fluoropolymer sponges for selective oil absorption and oil/water separation. ACS Appl. Mater. Interfaces 7, 4936-4946 (2015).

15. Liang, H. W. et al. Macroscopic-scale template synthesis of robust carbonaceous nanofiber hydrogels and aerogels and their applications. Angew. Chem. Int. Ed. 51, 5101-5105 (2012).

16. Gui, X. et al. Carbon nanotube sponges. Adv. Mater. 22, 617-621 (2010).

17. Nardecchia, S., Carriazo, D., Ferrer, M. L., Gutiérrez, M. C. \& del Monte, F. Three dimensional macroporous architectures and aerogels built of carbon nanotubes and/or graphene: synthesis and applications. Chem. Soc. Rev. 42, 794-830 (2013).

18. Yuan, J. et al. Superwetting nanowire membranes for selective absorption. Nat. Nanotechnol. 3, 332-336 (2008).

19. Adebajo, M. O., Frost, R. L., Kloprogge, J. T., Carmody, O. \& Kokot, S. Porous materials for oil spill cleanup: a review of synthesis. J. Porous Mater. 10, 159-170 (2003).

20. Olga, V. R., Darina, V. I., Alexandr, A. I. \& Alexandra, AO. Cleanup of water surface from oil spills using natural sorbent materials. Procedia Chem. 10, 145-150 (2014).

21. Sonmez, H. B. \& Wudl, F. Cross-linked poly(orthocarbonate)s as organic solvent sorbents. Macromolecules 38, 1623-1626 (2005).

22. Zhu, Q., Pan, Q. \& Liu, F. Facile removal and collection of oils from water surfaces through superhydrophobic and superoleophilic sponges. J. Phys. Chem. C 115, 17464-17470 (2011).

23. Wang, B. \& Guo, Z. Superhydrophobic copper mesh films with rapid oil/water separation properties by electrochemical deposition inspired from butterfly wing. Appl. Phys. Lett. 103, 063704 (2013).

24. Howarter, J. A. \& Youngblood, J. P. Amphiphile grafted membranes for the separation of oil-in-water dispersions. J. Colloid Interface Sci. 329, 127-132 (2009).

25. Yang, H. C. et al. Silica-decorated polypropylene microfiltration membranes with a mussel-inspired intermediate layer for oil-in-water emulsion separation. ACS Appl. Mater. Interfaces 6, 12566-12572 (2014).

26. Liu, H. et al. Flexible macroporous carbon nanofiber film with high oil adsorption capacity. J. Mater. Chem. A 2, 3557 (2014).

27. Turco, A. et al. A magnetic and highly reusable macroporous superhydrophobic/ superoleophilic PDMS/MWNT nanocomposite for oil sorption from water. J. Mater. Chem. A 3, 17685-17696 (2015).

28. Calcagnile, P. et al. Magnetically driven floating foams for the removal of oil contaminants from water. ACS Nano 6, 5413-5419 (2012).
29. Gui, X. et al. Magnetic and highly recyclable macroporous carbon nanotubes for spilled oil sorption and separation. ACS Appl. Mater. Interfaces 5, 5845-5850 (2013).

30. Li, L., Li, B., Wu, L., Zhao, X. \& Zhang, J. Magnetic, superhydrophobic and durable silicone sponges and their applications in removal of organic pollutants from water. Chem. Commun. 50, 7831-7833 (2014).

31. Wu, L., Li, L., Li, B., Zhang, J. \& Wang, A. Magnetic, durable, and superhydrophobic polyurethane@ $\mathrm{Fe}_{3} \mathrm{O}_{4} @ \mathrm{SiO}_{2} @$ fluoropolymer sponges for selective oil absorption and oil/water separation. ACS Appl. Mater. Interfaces https://doi.org/10.1021/ am5091353 (2015).

32. Abdulhussein, A. T., Kannarpady, G. K., Wright, A. B., Ghosh, A. \& Biris, A. S. Current trend in fabrication of complex morphologically tunable superhydrophobic nano scale surfaces. Appl. Surf. Sci. 384, 311-332 (2016).

33. Orbell, J. D., Godhino, L., Bigger, S. W., Nguyen, T. M. \& Ngeh, L. N. Oil spill remediation using magnetic particles: an experiment in environmental technology. J. Chem. Educ. 74, 1446 (1997).

34. Jin, Y. et al. Superhydrophobic and superoleophilic polydimethylsiloxane-coated cotton for oil-water separation process: an evidence of the relationship between its loading capacity and oil absorption ability. J. Hazard. Mater. 300, 175-181 (2015).

35. Cassie, B. D., Cassie, A. B. D. \& Baxter, S. Wettability of porous surfaces. Trans. Faraday Soc. 40, 546-551 (1944).

36. Wang, G. et al. Low drag porous ship with superhydrophobic and superoleophilic surface for oil spills cleanup. ACS Appl. Mater. Interfaces 7, 26184-26194 (2015).

37. Lu, Y. et al. Water droplets bouncing on superhydrophobic soft porous materials. J. Mater. Chem. A 2, 12177 (2014).

38. Xiong, Z. et al. Flexible PVDF membranes with exceptional robust superwetting surface for continuous separation of oil/water emulsions. Sci. Rep. 7, 14099 (2017).

39. Deng, X., Mammen, L., Butt, H. J. \& Vollmer, D. Candle soot as a template for a transparent robust superamphiphobic coating. Science 335, 67-70 (2012).

40. Choi, S. J. et al. A polydimethylsiloxane (PDMS) sponge for the selective absorption of oil from water. ACS Appl. Mater. Interfaces 3, 4552-4556 (2011).

41. Karatum, O., Steiner, S. A., Griffin, J. S., Shi, W. \& Plata, D. L. Flexible, mechanically durable aerogel composites for oil capture and recovery. ACS Appl. Mater. Interfaces 8, 215-224 (2016).

42. Yang, Y., Tong, Z., Ngai, T. \& Wang, C. Nitrogen-rich and fire-resistant carbon aerogels for the removal of oil contaminants from water. ACS Appl. Mater. Interfaces 6, 6351-6360 (2014).

43. Wang, G. \& Uyama, H. Facile synthesis of flexible macroporous polypropylene sponges for separation of oil and water. Sci. Rep. 6, 1-6 (2016).

44. Gui, X. et al. Recyclable carbon nanotube sponges for oil absorption. Acta Mater. 59, 4798-4804 (2011).

45. $\mathrm{Bi}, \mathrm{H}$. et al. Spongy graphene as a highly efficient and recyclable sorbent for oils and organic solvents. Adv. Funct. Mater. 22, 4421-4425 (2012).

46. Zhou, X., Zhang, Z., Xu, X., Men, X. \& Zhu, X. Facile fabrication of superhydrophobic sponge with selective absorption and collection of oil from water. Ind. Eng. Chem. Res. 52, 9411-9416 (2013).

47. Shang, Y. et al. An in situ polymerization approach for the synthesis of superhydrophobic and superoleophilic nanofibrous membranes for oil-water separation. Nanoscale 4, 7847 (2012).

48. Zhang, J. \& Seeger, S. Polyester materials with superwetting silicone nanofilaments for oil/water separation and selective oil absorption. Adv. Funct. Mater. 21, 4699-4704 (2011).

49. Luo, Y., Jiang, S., Xiao, Q., Chen, C. \& Li, B. Highly reusable and superhydrophobic spongy graphene aerogels for efficient oil/water separation. Sci. Rep. 7, 1-10 (2017).

50. Jiang, Z. R. et al. Coating sponge with a hydrophobic porous coordination polymer containing a low-energy CF3-decorated surface for continuous pumping recovery of an oil spill from water. NPG Asia Mater. 8, e253-e258 (2016).

51. Wang, C. et al. Facile approach in fabricating superhydrophobic and superoleophilic surface for water and oil mixture separation. ACS Appl. Mater. Interfaces 1, 2613-2617 (2009).

52. Lee, C. \& Baik, S. Vertically-aligned carbon nano-tube membrane filters with superhydrophobicity and superoleophilicity. Carbon N. Y 48, 2192-2197 (2010).

53. Wang, B., Liang, W., Guo, Z. \& Liu, W. Biomimetic super-lyophobic and superlyophilic materials applied for oil/water separation: a new strategy beyond nature. Chem. Soc. Rev. 44, 336-361 (2015).

54. Zhou, Z. \& Wu, X.-F. Electrospinning superhydrophobic-superoleophilic fibrous PVDF membranes for high-efficiency water-oil separation. Mater. Lett. 160, 423-427 (2015).

55. Zhang, J., Huang, W. \& Han, Y. A composite polymer film with both superhydrophobicity and superoleophilicity. Macromol. Rapid Commun. 27, 804-808 (2006). 
56. Rohrbach, K. et al. A cellulose based hydrophilic, oleophobic hydrated filter for water/oil separation. Chem. Commun. 50, 13296-13299 (2014).

57. Zhao, T., Zhang, D., Yu, C. \& Jiang, L. Facile fabrication of a polyethylene mesh for oil/water separation in a complex environment. ACS Appl. Mater. Interfaces 8 24186-24191 (2016).

58. Tai, M. H., Gao, P., Tan, B. Y. L., Sun, D. D. \& Leckie, J. O. Highly efficient and flexible electrospun carbon-silica nanofibrous membrane for ultrafast gravity-driven oil-water separation. ACS Appl. Mater. Interfaces 6, 9393-9401 (2014).

59. Liu, D., Yu, Y., Chen, X. \& Zheng, Y. Selective separation of oil and water with special wettability mesh membranes. RSC Adv. 7, 12908-12915 (2017).

60. Zhang, W. et al. Superhydrophobic and superoleophilic PVDF membranes for effective separation of water-in-oil emulsions with high flux. Adv. Mater. 25, 2071-2076 (2013).
Open Access This article is licensed under a Creative Commons Attribution 4.0 International License, which permits use, sharing, adaptation, distribution and reproduction in any medium or format, as long as you give appropriate credit to the original author(s) and the source, provide a link to the Creative Commons license, and indicate if changes were made. The images or other third party material in this article are included in the article's Creative Commons license, unless indicated otherwise in a credit line to the material. If material is not included in the article's Creative Commons license and your intended use is not permitted by statutory regulation or exceeds the permitted use, you will need to obtain permission directly from the copyright holder. To view a copy of this license, visit http://creativecommons. org/licenses/by/4.0/.

(c) The Author(s) 2019 